\title{
Polymer-derived ceramic/graphene oxide architected composite with high electrical conductivity and enhanced thermal resistance
}

Benito Román-Manso ${ }^{1}$, Juan J. Moyano, Domingo Pérez-Coll, Manuel Belmonte, Pilar Miranzo and M. Isabel Osendi*

Institute of Ceramics and Glass (ICV), CSIC Campus Cantoblanco. Madrid, 28049. Spain.

\begin{abstract}
A low temperature method for the fabrication architected graphene containing ceramic composites is developed based on the infiltration of lightweight graphene oxide (GO) micro-lattices with a preceramic polymer. Self-supported highly porous threedimensional (3D) GO structures fabricated by direct ink writing are infiltrated with a liquid organic-polysilazane (a compound of $\mathrm{Si}, \mathrm{C}, \mathrm{H}, \mathrm{N}$ ), and subsequently pyrolyzed at temperatures of $800-1000^{\circ} \mathrm{C}$ to favor the ceramic conversion. Accordingly, these ceramic composites replicate the patterned GO skeleton and whereas the graphene network provides the conductive path for the composite (electrical conductivity in the range $0.2-4 \mathrm{~S} \mathrm{~cm}^{-1}$ ), the wrapping ceramic affords a protective barrier against atmosphere, temperature (up to $900{ }^{\circ} \mathrm{C}$ in air) and even direct flame. These structured composites also show hydrophobicity (wetting angle above $120^{\circ}$ ) and better load bearing capacity than the corresponding 3D GO lattice. The process is very versatile and could be applied for different liquid precursors.
\end{abstract}

\section{Introduction}

Additive manufacturing methods have lately been gaining much attention as freeforming routes for creating very diverse and complex-shaped materials. Among these methods, direct ink writing (DIW) emerges as a fabrication technique that allows complex patterns and highly porous, and even hierarchical structures [1,2]. In particular, the robotic filament deposition uses colloidal inks with a particular pseudoplastic rheology to build self-supporting 3D structures in the green stage printed in a layer-bylayer fashion. This technique (also known as robocasting) is commonly used to create $3 \mathrm{D}$ ceramic structures from a highly concentrated and flocculated aqueous powders suspension [1]. Recently, it has also been employed in a number of cases for assembling multilayer graphene [3] and GO [4-6] into architected structures by developing suitable

* Corresponding author (M. I. Osendi) E-Mail: miosendi@icv.csic.es, tel.: +34917355840

${ }^{1}$ BRM Present address: School of Engineering and Applied Sciences, Harvard University 52, Oxford St, 02318 Cambridge MA, USA. 
inks. These 3D graphene-based structures show low density $\left(\rho \leq 0.4 \mathrm{~g} \mathrm{~cm}^{-3}\right)$, particularly those containing GO sheets $\left(\rho \leq 0.1 \mathrm{~g} \mathrm{~cm}^{-3}\right)$, because of the very low solid concentration of the aqueous inks generally resulting from the well exfoliated GO sheets. Increases of electrical conductivity were reported for these GO structures after high temperature treatments that eliminated printing additives and promoted GO reduction as well [4-6].

Of particular interest and complexity are preceramic polymers as they are converted into ceramics when heat-treated above certain temperature, thus offering advantages as plastic-forming [7] or the possibility of using infiltration methods for the production of continuous fiber/ceramic matrix composites, thus avoiding costly machining and high sintering temperatures. Accordingly, they are increasingly used in the industrial practice [8]. With thermal treatments, preceramic polymers evolve first into an infusible body and later into a ceramic material, with elimination of different organic groups and corresponding increases in density.

Preceramic polymers have been employed to make cellular structures [7], but their use for making architected materials is scarce. Recently, 3D SiOC ceramic structures manufactured by stereolithography using UV curable preceramic polymers were reported $[9,10]$ that showed remarkable thermal and mechanical endurances have been reported [9]. If we focus on 3D ceramic/graphene composite structures processed from preceramic polymers, we find only one work reporting the DIW of a polysiloxane type polymer with GO fillers [10], although no properties have been reported for these structures. To fill these gap, in this work we propose a novel route to build complex composite structures consisting in infiltrating 3D GO lattices printed using robotic deposition with a preceramic polymer, which is converted into amorphous ceramics, and also providing results of their outstanding properties. A type of organopolysilazane is chosen for present research because it is a low viscosity liquid, commercially produced, and has been widely investigated. Organopolysilazanes are preceramic polymers that contain carbon groups, such as methyl or vinyl appended to silicon or nitrogen atoms within the polymer chain [11]. When thermal treated under inert conditions, organopolysilazanes yield a $\mathrm{SiCN}$ (silicon carbonitride) amorphous ceramics at low pyrolysis temperature and $\mathrm{Si}_{3} \mathrm{~N}_{4}$ and $\mathrm{SiC}$ nano-sized regions after heating at high temperature $\left(\mathrm{T} \geq 1200{ }^{\circ} \mathrm{C}\right)$ [7]. One main drawback of preceramic polymers is the extensive cracking produced during the ceramic conversion associated to the large 
shrinkages, the increase of density and the internal pressure built-up produced by released gas species $[7,11,12]$. Accordingly, preceramic polymers have been very successful in achieving ceramic fibers and coatings and more challenging in the case of massive materials [12]; although this effect may be, if not thoroughly suppressed, at least considerable reduced by maintaining a low dimension of the polymer shell during the infiltration/pyrolysis process [11,12].

Present process has the ability of tailoring architected structures of ceramized polymers containing fully connected GO inclusions, thus assuring functional characteristics such as electrical conduction but also offering protection to the GO structure against temperature and environment by the enveloping ceramic. The method has the additional advantage of using an environmentally-friendly aqueous solvent to achieve the printable ink; by contrast, an aprotic organic solvent would have been necessary for the DIW of the preceramic polymer/GO mix due to the reactivity of this polymer with water. As a final remark, it is worth to mention that any other low-viscosity liquid precursor could have been equally used as the small size of the printed GO micro-lattices ( $300 \mu \mathrm{m}$ diameter) and their high porosity facilitates the penetration throughout the scaffold.

\section{Experimental}

\subsection{Sample preparation}

For the printing of GO structures, aqueous GO gels were first developed with polymeric additives. In particular, an aqueous solution consisting of both high and low-molecularweight polyethylenimine (H-PEI, Mw $=25000 \mathrm{~g} \mathrm{~mol}^{-1}$; L-PEI, Mw $=2000 \mathrm{~g} \mathrm{~mol}^{-1}$ in a 50 wt. \% aqueous concentration; both from Aldrich Chemical Co., USA) was formed. Subsequently, the GO suspension was obtained by adding, in several steps, GO powders (Angstron Materials Inc., USA, N002-PDE) with nominal dimensions of 2-3 nm thickness and length $\leq 7 \mu \mathrm{m}$ in the $\mathrm{x}-\mathrm{y}$ plane. After each addition, the suspension was homogenized in a planetary centrifugal mixer (AR-250; Thinky Company, USA). Simultaneously, an aqueous solution of polyethylene glycol (PEG, Mw= $8000 \mathrm{~g} \mathrm{~mol}^{-1}$, 60 wt.\%; Fisher Scientific, USA) was added to the suspension to prevent phase segregations during ink extrusion. Once all components were included in the mixture, the colloidal gel was again homogenized by high-shear mixing. Therefore, the final 
paste was formed by deionized water, GO powders, H-PEI, L-PEI and PEG in a fixed weight proportion of 83.4:5.0:6.7:1.3:3.6, respectively.

The colloidal stability of GO and PEI-coated GO powders was analyzed in dilute suspensions (0.01 wt.\%) with a short equilibrium time $(1 \mathrm{~min})$. Zeta potential measurements (Zetasizer Nano-ZS, Malvern, UK) were carried out as a function of $\mathrm{pH}$ and adjusted in the acidic and alkaline range using $1 \mathrm{M} \mathrm{HCl}$ and $\mathrm{KOH}$ solutions.

For the GO gels, the shear flow and shear elastic modulus were analyzed with a rheometer (CVO 100 D, Bohlin Instruments, UK) equipped with cone-and-plate geometry (diameter: $40 \mathrm{~mm}$; cone angle: $4^{\circ}$ ). The rheometer measuring system was covered with a fitting tool to reduce evaporation. The apparent viscosity $\left(\eta_{\text {app }}\right)$ of the inks was measured as a function of shear rate $\left(0.1<\dot{\gamma}<200 \mathrm{~s}^{-1}\right)$ at 23 discrete points with logarithmic spacing, in increasing and decreasing slopes. Additionally, oscillation measurements were performed at a frequency of $1 \mathrm{~Hz}$ for the characterization of the elastic $\left(G^{\prime}\right)$ and viscous $\left(G^{\prime \prime}\right)$ moduli of the pastes, applying ascending shear stress $(\tau=$ 1-1500 Pa) and considering test points with logarithmic spacing.

\subsection{Printing process}

Periodic lattices were designed with the Robocasting software (RoboCAD 4.2, 3-D Inks LLC, Stillwater, OK) and printed with a three-axis Robocasting system (A3200, 3-D Inks LLC) at room temperature. The colloidal GO-based inks were first loaded into a syringe (barrel diameter $=9.5 \mathrm{~mm}$, volume $=3 \mathrm{cc}$; EFD Inc., East Providence, RI) and placed into the syringe holder of the robocasting system. The inks were extruded in air through nozzles with different diameters 250-330 $\mu \mathrm{m}$ (Precision Tips; EFD Inc.) onto flat alumina substrates. The extrusion speed of the ink was controlled by an automatic feed system at a constant volumetric flow rate of $0.25 \pi \mathrm{D}^{2} v$, where $\mathrm{D}$ is the nozzle diameter and $v$ is the constant $\mathrm{x}-\mathrm{y}$ table speed $\left(8 \mathrm{~mm} \cdot \mathrm{s}^{-1}\right)$. Lattices were constructed by depositing a linear array of parallel filaments in the $\mathrm{x}-\mathrm{y}$ plane, each array shifted by $90^{\circ}$ in adjacent layers, having typically 24 layers and edge dimensions of $12 \mathrm{~mm}$. After printing, the GO periodic structures were oven dried at $\sim 80^{\circ} \mathrm{C}$ for $15 \mathrm{~min}$ and immediately afterwards frozen in a refrigerator at $-20{ }^{\circ} \mathrm{C}$. This partial drying step helps eliminate water that would otherwise cause a network of evenly spaced cracks in the structures during freezing. Finally, these as-prepared GO scaffolds were lyophilized in a freeze-drier (Freezone Plus 12L, Labconco Corp. USA) to sublimate the ice. Finally, 
structures were impregnated with a commercial poly-vinylsilazane, labelled as PSZ (Durazane HTT1800, AZ Electronic Materials GmbH, Germany), by immersion in this liquid precursor during several hours to assure the penetration of the liquid within the scaffold rods and, then, removing the excess of polymer. This process was aided by sonicating the immersed GO structures. The impregnated scaffolds were held onto a Pt foil in alumina crucibles and treated in a tubular electric furnace at different temperatures ( 800 and $1000{ }^{\circ} \mathrm{C}$ ) under a continuous $\mathrm{N}_{2}$ flow during the whole cycle. The heating ramps used were kept constant at $2{ }^{\circ} \mathrm{C} \mathrm{min}^{-1}$, and the dwelling times were always 5 min. For comparative purposes, some GO bare structures were heat treated at $800{ }^{\circ} \mathrm{C}$ in $\mathrm{N}_{2}$.

\subsection{Characterization of the structures}

The weight loss of the bare GO scaffolds with temperature was measured in a thermogravimetric analyzer (TGA Q500 V6.3 Build 189, TA Instruments, USA), both in air and $\mathrm{N}_{2}$. Similarly, the weight loss of the polymer was recorded up to $1000{ }^{\circ} \mathrm{C}$ in $\mathrm{N}_{2}$. The Density of the specimens was estimated by weighing and measuring the specimens with a caliper. The crystalline quality of the specimens was identified by the use of X-ray diffraction (XRD, Bruker, D8 Advance, USA). The microstructure of these architected composites was studied by field emission scanning electron microscopy (FESEM, S4700, Hitachi, Japan). High resolution transmission electron microscopy (HRTEM, JEOL 2100, Japan operating at $200 \mathrm{KV}$ ) was used to observe the ceramic conversion in the polymer on mortar crushed specimens. Spatial distribution of the GO network and the converted polymer was visualized with the help of confocal Raman spectroscopy (Alpha300, WItec, Germany). Elemental analyses of C, N, O and H in the polymer and infiltrated structures were done using two LECO apparatus (CHNS-932 and TC-500). The elemental content of Si was estimated by difference.

For the electrical conductivity measurements as a function of temperature, both bare GO structures and composite scaffolds, heat-treated at 800 and $1000{ }^{\circ} \mathrm{C}$, were used. Electrodes were painted on opposite faces of the scaffolds in the longitudinal direction relative to the printed rods using silver paste (Electrolube, ERSCP03B) and connected to Pt wires assuring a good electrical contact. Two Pt wires were used to generate the current flow through the system and another pair served to read the voltage drop in the sample. Electrical resistance data were obtained from the current-voltage curves. The experimental procedure was performed by galvanostatic linear sweep voltammetry 
using a potentiostat/galvanostat (Autolab PGSTAT302N, Switzerland) in the current range of 1-10 mA. The apparent electrical conductivity of the structures was calculated according to the formula $\sigma=\mathrm{L}(\mathrm{R} \mathrm{S})^{-1}$ where $\mathrm{R}$ is the electrical resistance of the sample, $\mathrm{S}$ is the electrode surface area, and $\mathrm{L}$ is the distance between the electrodes. Air and $\mathrm{N}_{2}$ atmospheres were used for the measurements.

Wetting experiments where done over the infiltrated and pyrolyzed structures by measuring the water contact angle in air. A GO/PSZ structure pyrolyzed at $800{ }^{\circ} \mathrm{C}$ was heated with a micro-torch gas burner with a butane/air mixture during $\sim 30 \mathrm{~s}$, and repeated for 3 cycles. The temperature on the exposed surface of the structure was recorded with a thermal imaging infrared camera (FLIR A325sc), thus obtaining the temperature profile of the specimen with time averaged over the exposed surface. A similar experiment was performed with a bare GO printed structure (after lyophilization), although in this case only one heating cycle was possible.

Two scaffolds (typically of $10 \times 10 \times 4$, in mm) of each composition (bare GO and GO/PSZ composite) were compression tested using an universal testing machine (ZwickiLine Z5.0TS, Zwick-Roell, Germany) in displacement control mode at a rate of $0.5 \mathrm{~mm} \cdot \mathrm{min}^{-1}$ until crushing. The specimens were previously smoothly flattened with $\mathrm{SiC}$ grinding paper at the top/bottom surfaces (cell-side) to ensure a homogeneous distribution of the load on the whole structure. Strain was approximated from the displacement and the specimen height. Strength was calculated from the maximum load reached in the tests and the loaded lattice surface.

\section{Results and discussion}

Zeta potential measurements of bare GO sheets served to identify its isoelectric point (IEP). As shown in Fig. 1a, IEP is 1.5, and the GO sheets are negatively charged in almost the whole $\mathrm{pH}$ range, which is attributed to the ionization of the carboxylic acid on the edge of bare GO sheets [13]. However, when adding PIE the IP turned to basic values $\sim 11$ ( Fig. 1a) owing to the PEI adsorbed on the surface of GO sheets, providing an electrosteric stabilization [14] that significantly increased the concentration of colloidal particles in suspension. Accordingly, higher solids contents (5.2 wt.\% GO equivalent to $2.45 \mathrm{vol} . \%$ ) than previously published data were achieved, i.e. between $1.75-3.0 \mathrm{wt} . \%$ for a responsive polymer surfactant [5] or $\sim 1.3 \mathrm{wt} . \%$ for plain aqueous 
suspensions [15]. The colloidal GO gel was completed with the addition of polyethylene glycol that prevents phase segregations. In Fig. 1b, a log-log plot of the apparent gel viscosity, $\eta_{\text {app }}$, is given for increasing and decreasing shear rates, $\dot{\gamma}$, indicating highly shear thinning characteristics and a very good recovery of $\eta_{\text {app }}$ at rest. This pseudoplasticity enables smooth extrusion at low pressures in the working region of $\dot{\gamma}=$ $30-70 \mathrm{~s}^{-1}$, as well as the retention of the shape of the overall structures once printed.
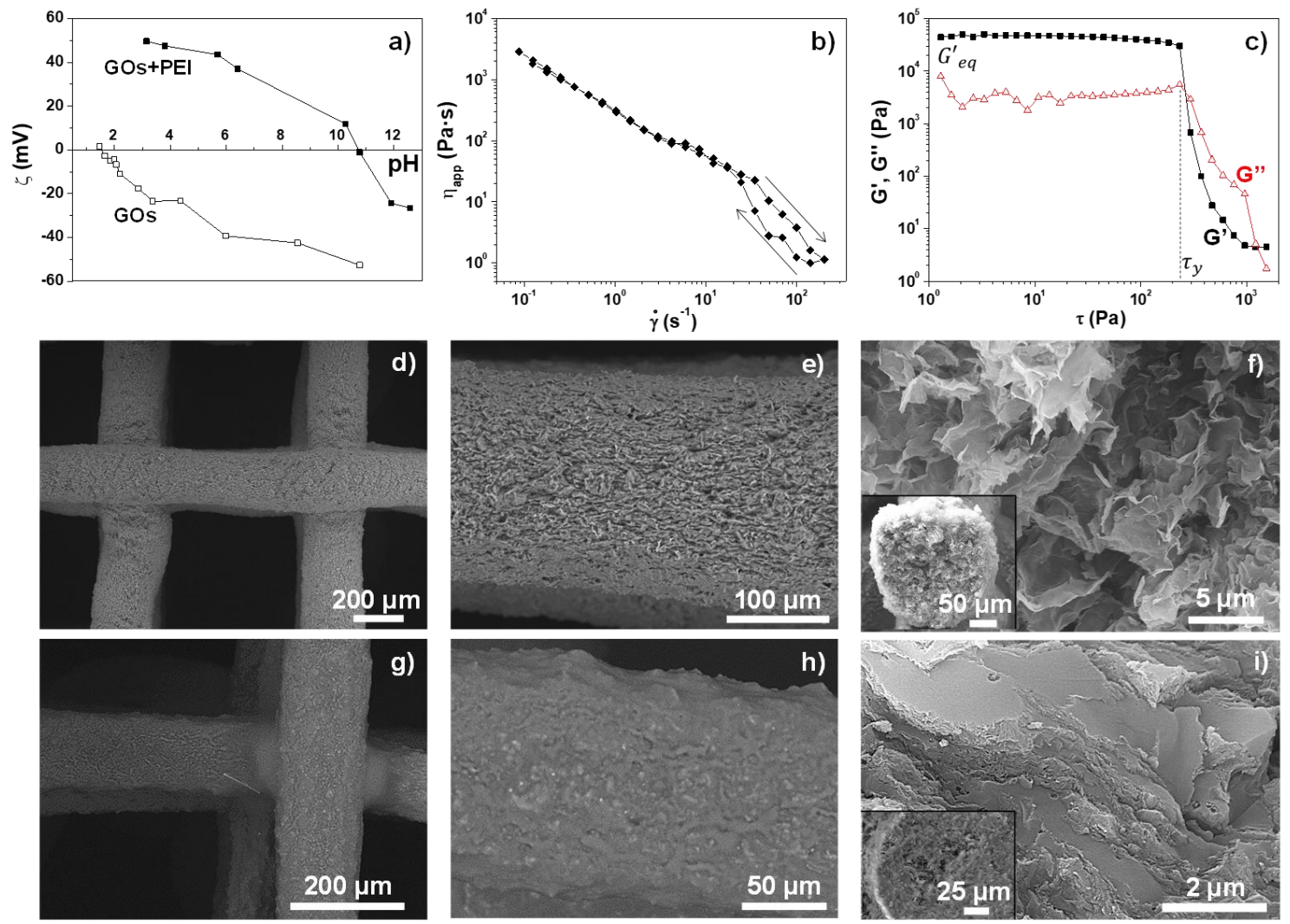

h)

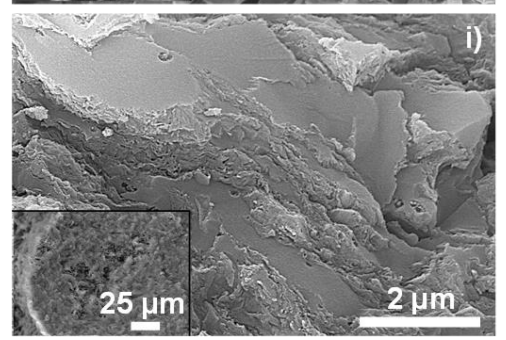

Fig. 1. (a) Zeta potential (ל) measurements plotted as a function of $\mathrm{pH}$ values for GO and GO-PEI suspensions. (b) Apparent viscosity ( $\left.\eta_{\text {app }}\right)$ versus shear rate $(\dot{\gamma})$ of GObased printable inks. (c) Elastic $\left(G^{\prime}\right)$ and viscous $\left(G^{\prime \prime}\right)$ moduli versus shear stress $(\tau)$ plots where the elastic modulus of equilibrium $\left(\mathrm{G}_{\text {eq }}^{\prime} \sim 46 \mathrm{kPa}\right)$ and yield stress $\left(\tau_{\mathrm{y}} \sim 0.22\right.$ $\mathrm{kPa}$ ) are pointed. SEM micrographs of a GO lattice after dying/lyophilization steps showing a top view (d), the surface of an extruded filament (e) and a cross section view at two magnifications of a GO filament after treatment at $800{ }^{\circ} \mathrm{C}$ in $\mathrm{N}_{2}$ (f). Analogous SEM images of a PSZ infiltrated GO lattice pyrolyzed at $800{ }^{\circ} \mathrm{C}$ in $\mathrm{N}_{2}$, (g) top view, (h) filament and (i) cross section at different magnifications. 
Fig. 1c shows that $G^{\prime}$ exhibits a linear viscoelastic plateau that defines the equilibrium modulus $\left(\mathrm{G}^{\prime}{ }_{\mathrm{eq}}\right)$, and a sudden decline at high shear stresses upon a certain threshold that defines the yield stress $\left(\tau_{\mathrm{y}}\right)$. A similar trend is observed for $\mathrm{G}^{\prime \prime}$, that overpasses $\mathrm{G}^{\prime}$ for high shear rates. The printable GO gel exhibited values of $\mathrm{G}_{\text {eq }}^{\prime} \approx 46 \mathrm{kPa}$ and $\tau_{\mathrm{y}} \approx 0.22$ $\mathrm{kPa}$ comparatively higher than those reported for $\mathrm{GO}$-water dispersions $\left(\mathrm{G}^{\prime} \mathrm{eq}=0.4 \mathrm{kPa}\right.$ and $\tau_{\mathrm{y}} \approx 0.03 \mathrm{kPa}$ at $0.6 \mathrm{vol} . \%$ ) [15], although lower than those of graphene nanoplatelets printable inks $\left(\mathrm{G}_{\mathrm{eq}}^{\prime} \approx 300 \mathrm{kPa}\right.$ and $\left.\tau_{\mathrm{y}} \approx 0.7 \mathrm{kPa}\right)[3]$-explainable by the much higher solid contents of the latter (34 wt.\%). Nevertheless, present ink still proved enough strength to maintain the shape of the extruded filaments and the morphology of the lattice structures, also showing a correct deposition (Fig. 1d). Rheological features of the GO-based gel assured adequate printing, even without adding any flocculants to collapse the electrosteric forces of PEI-coated GO as the $\mathrm{pH}$ of the ink was close to the IEP.

Figs. 1d and 1e display top views of a lyophilized GO lattice at different magnifications. The quick drying treatment -previous to the lyophilization- produced a linear shrinkage of the structures $(\sim 25 \%)$ and corresponding increase of their density $\left(\rho \sim 0.2 \mathrm{~g} \mathrm{~cm}^{-3}\right)$ compared to the structures without it $\left(\rho<0.1 \mathrm{~g} \mathrm{~cm}^{-3}\right)$, besides produced the soft hardening of the polymer surfactants. Yet these 3D printed structures were very light, presenting $90 \%$ porosity, shared by the structure geometry itself $(\sim 40 \%)$, as calculated by the expression $P_{g}=1-\frac{\pi \Phi^{2}}{2 \mathrm{ah}}$, given in [16] and where $\Phi, a$ and $h$ are geometric parameter of the structure (rod diameter, and distances between adjacent rods, and consecutive layers, respectively), and by the skeleton (50\%). A cross-section image of a GO filament (Fig. 1f) after treatment at $800{ }^{\circ} \mathrm{C}$ in $\mathrm{N}_{2}$ shows the open porous structure of entangled sheets.

The infiltration of porous mats by melts or liquids is governed by the viscosity of the melt and the wetting ability of the liquid [17]. Present polymer presents low viscosity $(21.5 \mathrm{mPa} \cdot \mathrm{s})$ [18] and when a drop of PSZ is cast over a compacted surface of GO powders ( just die pressed) it rapidly spreads, thus indicating good wettability (See Supplementary data, Fig. S1), and accordingly favoring the complete infiltration of the printed GO structures as shown in Figs. 1g, $1 \mathrm{~h}$ and 1i. After infiltration the structure gains some weight, in such a way that the structured GO/PSZ composite contains about $50 \mathrm{wt} . \%$ of polymer, which actually matches the open porosity of the GO skeleton. 
It is enlightening to observe the transformations during heating of the GO and the polymer separately. TGA of the original GO powder indicates a weight loss close to 10 $\%$ between $\mathrm{RT}$ and $500{ }^{\circ} \mathrm{C}$ in $\mathrm{N}_{2}$, whereas for the printed $\mathrm{GO}$ structure (lyophilized) a different profile is observed due to the absorbed polyelectrolytes (PEI and PEG) in the ink with $\sim 70 \%$ mass loss for the same interval. Conversely, under air conditions the printed GO ink completely evanesces at $500{ }^{\circ} \mathrm{C}$ (Fig. 2a). On the other hand, the crosslinked polymer $\left(200{ }^{\circ} \mathrm{C}\right.$ treatment in $\left.\mathrm{N}_{2}\right)$ experiences a weight loss of $\sim 23 \%$, which gives a ceramic yield of $77 \%$ (Fig. 2b) and the corresponding mass spectrometry analyses reveal that the volatile species evolving are $\mathrm{NH}_{3}$ (atomic mass $\mathrm{m} / \mathrm{e}=17$ ) in the interval $200-400{ }^{\circ} \mathrm{C}$ and $\mathrm{CH}_{4}(\mathrm{~m} / \mathrm{e}=15)$ for the $500-800{ }^{\circ} \mathrm{C}$ range; whereas, $\mathrm{H}_{2} \mathrm{O}(\mathrm{m} / \mathrm{e}$ $=18$ ) is released in the whole interval (Fig. 2c).

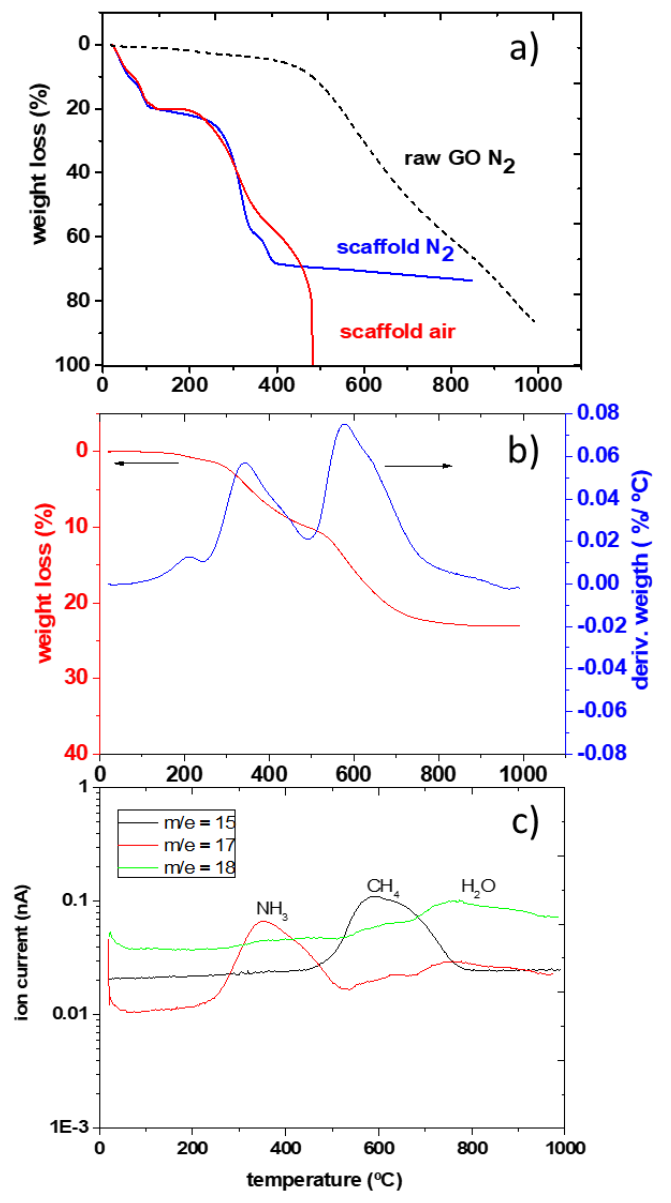

Figure 2. (a) TGA curves comparing weight loss of the original GO powders (in $\mathrm{N}_{2}$ ) and the GO structure (after lyophilization) in air and $\mathrm{N}_{2}$ atmospheres, as shown in the legends. (b) TGA of cross-linked polymer $\left(200{ }^{\circ} \mathrm{C}\right.$ in $\left.\mathrm{N}_{2}\right)$. (c) TGA mass spectra for the cross-linked polymer in b) with corresponding atomic mass of the volatile species produced. 
The impregnated GO structure after pyrolysis at $800{ }^{\circ} \mathrm{C}$ experiences $\sim 50 \%$ weight loss that approximately corresponds to individual mass losses faced by PSZ and the GO structure weighted by their proportions in the $3 \mathrm{D}$ composite. A simple calculation considering the weight loss for each component, $\mathrm{PSZ}$ and $\mathrm{GO}$, up to $800{ }^{\circ} \mathrm{C}$ gives a 70 wt. \% of converted polymer in the composite. The elemental composition of the PSZ and infiltrated structures after pyrolysis are compared in Table 1, showing a remarkable increase in the oxygen content for the composite material (from 1.7 to $22.0 \mathrm{wt} . \%$ ). If we estimate the $\mathrm{C}$ associated to the converted polymer in the composite (by comparing with the $\mathrm{Si} / \mathrm{C}$ ratio in the PSZ- $800{ }^{\circ} \mathrm{C}$ ) and assuming that the difference in $\mathrm{C}$ content (around 9 wt.\%) pertains to the GO structure, the associated oxygen content supposing it was not reduced at all would be in the order of $1.8 \mathrm{wt} . \%$ at the most, which is clearly much lower than the measured value. Accordingly, the increment in oxygen cannot be attributed to the GO network, instead, the polymer intakes much of that oxygen (between 18-19 wt.\%) during the infiltration process, ant it remains in its structure after the ceramic conversion, hence developing a SiOCN amorphous phase. Hence the final amount of converted polymer in this composite must be incremented by this excess $\mathrm{O}_{2}$, thus giving $~ 90 \mathrm{wt} . \%$ of SiCON and the rest, $10 \mathrm{wt}$. \%, corresponding to GO. If needed, this effect could be avoided by performing the infiltration process in an inert atmosphere.

Table 1. Elemental analysis for the PSZ polymer and the infiltrated material, GO/PSZ

\begin{tabular}{llllll}
\hline & $\mathbf{C}[w t . ~ \%]$ & $\mathbf{N}$ & $\mathbf{S i}^{\mathbf{a})}$ & $\mathbf{O}$ & $\mathbf{H}$ \\
\hline PSZ-800 $^{\circ} \mathbf{C}$ & 18.0 & 22.0 & 57.0 & 1.7 & 1.3 \\
\hline $\mathbf{G O}^{\circ} \mathbf{P S Z - ~ 8 0 0}{ }^{\circ} \mathbf{C}$ & 21.0 & 16.0 & 38.6 & 22.0 & 2.4 \\
\hline
\end{tabular}

a) estimated by difference

No substantial cracking (Fig. $1 \mathrm{~g}$ and $1 \mathrm{~h}$ ) is detected in the infiltrated structures after pyrolysis $\left(800-1000{ }^{\circ} \mathrm{C}\right)$, remaining essentially amorphous according to the XRD analyses (see supplementary data, Fig. S2). The closely intertwined GO sheets in the structures (see Fig. 1f) probably inhibit such effect by reducing polymer shrinkage in a similar manner as verified for inert fillers [7,12]. Micro-Raman spectra of GO/PSZ structures are also featureless as they showed very high fluorescence, nevertheless some 
informative features were derived from the study. In fact, Raman intensity maps reveal two distinct interpenetrating zones (brilliant and dark in the maps) for the thermally treated GO/PSZ structures (Fig. 3a and 3b). The brilliant zones in the maps are ascribed to the converted polymer owing to its reported fluorescence effect [19], which is observed in spectra 1 and 2 of Fig. 2c. Conversely, the dark regions (Fig. 2a and 2b) show spectra with low intensity background (as spectrum 3 in Fig. 2c) overlain with two small peaks (see inset in Fig. 3c) characteristics of carbon materials [20] -D and G bands, around 1350 and $1580 \mathrm{~cm}^{-1}$ of Raman shift. The high D/G intensity ratio is typical of a defective graphene structure, hence most probably pertaining to the GO network. Interestingly, the brilliant regions in the mapping of GO/PSZ specimen for the $1000{ }^{\circ} \mathrm{C}$ treatment (Fig. 2b) show characteristic spectra with perceptible D and G peaks, which could be initially associated to interference of the GO network, but which are in fact due to the segregation of graphitic regions in the polymer itself as ensuing TEM observations indicate.
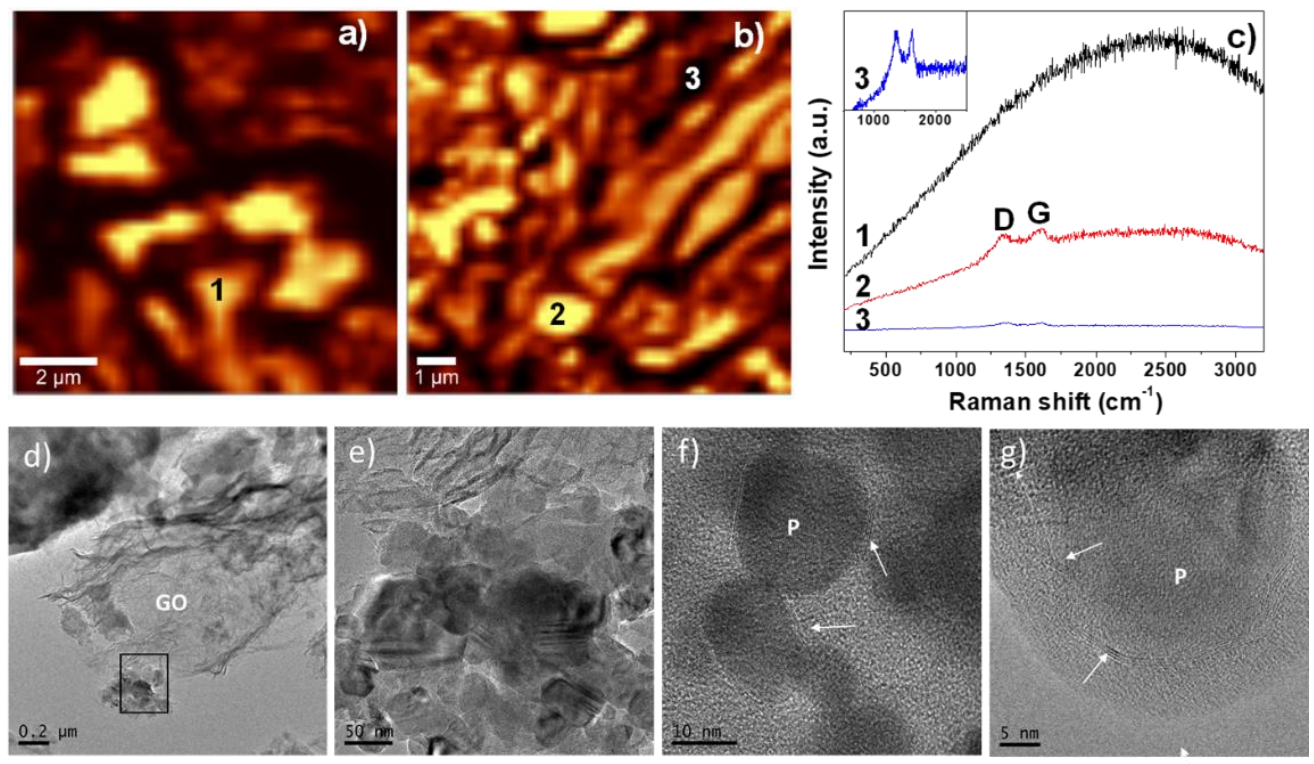

Fig. 3. Raman maps of the integrated intensity of the fluorescence band (200-3000 cm in a GO/PSZ composite, treated at a) $800{ }^{\circ} \mathrm{C}$ and b) $1000{ }^{\circ} \mathrm{C}$. c) Single Raman spectra corresponding to marked areas in the maps, representative of the amorphous ceramic regions in the bright areas $(1,2)$ and the defective graphitic regions in the darker ones (3) (the inset graph being an enlargement of spectrum 3). TEM images of the same material $\left(800{ }^{\circ} \mathrm{C}\right.$ treatment) where large crumpled GO sheets with attached particles are observed (d). Enlarged view of black framed region in d) displaying GO sheets at the top of the image and ceramized polymer at the bottom. HRTEM image (f) showing 
turbostratic graphitic domains (pointed by arrows) frequently circumventing crystalline small particles (marked as $\mathrm{P}$ ) both imbedded in the amorphous surroundings. g) Image at higher magnification revealing a graphitic string encircling a particle in the ceramized polysilazane.

A higher magnification view of the 3D GO/PSZ composite (pyrolyzed at $800{ }^{\circ} \mathrm{C}$ ) by TEM indicates the presence of large wrinkled sheets of GO with adhered particles as seen in the framed region of Fig. 3d and the enlarged image of same area in Fig. 3e. The HRTEM images in those regions show the nucleation of turbostratic graphitic domains (Figs. $3 \mathrm{f}$ and $3 \mathrm{~g}$ ) and rounded crystalline grains $(<10 \mathrm{~nm}$ ). Similar features are also observed in the converted polymer alone $\left(800{ }^{\circ} \mathrm{C}\right.$ treatment), where incipient crystallization of $\alpha-\mathrm{SiC}$ was detected (Supplementary data, Fig. S3). Nonetheless, for treatments at even higher temperatures $\left(>1000^{\circ} \mathrm{C}\right)$ the evolution of present $\mathrm{SiOCN}$ matrix phase would be different that for the parent polysilizane ( $\mathrm{SiCN}$ ) as crystallization processes in polymer precursors are very dependent on the molecular structure and composition of the preceramic polymer $[10,12]$.

Both the 3D GO and GO/PSZ structures show rising electrical conductivity with temperature as depicted in Fig. 4a. In particular, the bare 3D GO structure treated at 800 ${ }^{\circ} \mathrm{C}$ displays $\sigma$ values in the range of $0.50-1.0 \mathrm{~S} \mathrm{~cm}^{-1}$ in the RT- $200{ }^{\circ} \mathrm{C}$ interval but it rapidly decreases above this temperature (in air conditions) until the collapse of the structure (at $\sim 400{ }^{\circ} \mathrm{C}$ ), in agreement with TGA results for the GO scaffold in air (Fig. 2a). Conversely, conductivity of the GO structure tested in $\mathrm{N}_{2}$ increases with temperature up to $750{ }^{\circ} \mathrm{C}$ (reaching $\sigma=2.16 \mathrm{~S} \mathrm{~cm}^{-1}$ ), and then drops at $800{ }^{\circ} \mathrm{C}$ that coincides with the previous treatment temperature. This effect could be caused by weakening by a further reduction of the GO structure, thus affecting the number of conducting paths.

On the other hand, the range of stability in air increases up to $750{ }^{\circ} \mathrm{C}$ for the $3 \mathrm{D}$ GO/PSZ material pyrolyzed at $800{ }^{\circ} \mathrm{C}$, although showing values of $\sigma$ slightly lower than those of the bare GO structure owing to the essentially insulating nature of the polymer [21]. The conductivity of the $3 \mathrm{D}$ GO/PSZ structure under $\mathrm{N}_{2}$ testing conditions shows a very similar trend but with slightly higher $\sigma$ values in the whole interval, confirming its stability (Fig. 3a). The composite structure pyrolyzed at $1000{ }^{\circ} \mathrm{C}$ experiences an increase in $\sigma$ when compared to the materials treated at $800{ }^{\circ} \mathrm{C}$, probably because 
further reduction of the GO network occurred, displaying a steady increase with temperature up to $350{ }^{\circ} \mathrm{C}$ followed by an abrupt decrease at $400{ }^{\circ} \mathrm{C}$ for the specimen tested in air, whereas for the sample tested in $\mathrm{N}_{2}, \sigma$ shows a continuous increase up to $800{ }^{\circ} \mathrm{C}$. The decline of $\sigma$ in air for the GO/PSZ structure treated at $1000{ }^{\circ} \mathrm{C}$ seems linked to extensive cracking occurring in the ceramic shell during testing. In fact, after the treatment at $1000{ }^{\circ} \mathrm{C}$ few cracks are observed that could be due to the progressive crystallization of the amorphous phase, intensified under the testing conditions (see supplementary data, Fig. S4), thus producing additional cracking that evidently reduced the protection of the GO/PSZ structure in air because exposes the GO network. Accordingly, the temperature of $1000{ }^{\circ} \mathrm{C}$ is probably the upper limit for the pyrolysis treatment of these infiltrated structures.

It can be illustrative comparing present conductivity data at RT with previous results for $3 \mathrm{D}$ graphene-based structures. For bare GO structures of low density $\left(\rho \leq 100 \mathrm{mg} \mathrm{cm}^{-3}\right)$, $\sigma$ in the range 0.02-3.00 $\mathrm{S} \mathrm{cm}^{-1}$ have been reported [4-6] (green encircled in Fig. 4b), typically showing a log-plot scale with density. Therefore, $\sigma$ of present GO structure fits this trend and approaches the upper side of this range (Fig. 3b). Obviously, $\sigma$ of 3D structures printed using pristine graphene nanoplatelets (GNP) is above that range [3] (Fig. 4b) as they have higher density and lower oxygen content. Current GO/PSZ composite structures compare favorably with previous results for printed graphene composites (purple encircled in Fig. 4b), as they present room temperature $\sigma$ values similar to that of a 3D GNP/SiC crystalline composite with 20 vol.\% GNP, sintered at $1800{ }^{\circ} \mathrm{C}[16]$ and higher than $\sigma$ for 3D hybrid graphene structures obtained with a printable biopolymer [22] or using a thermoplastic material [23], being relatively lighter structures as well. 

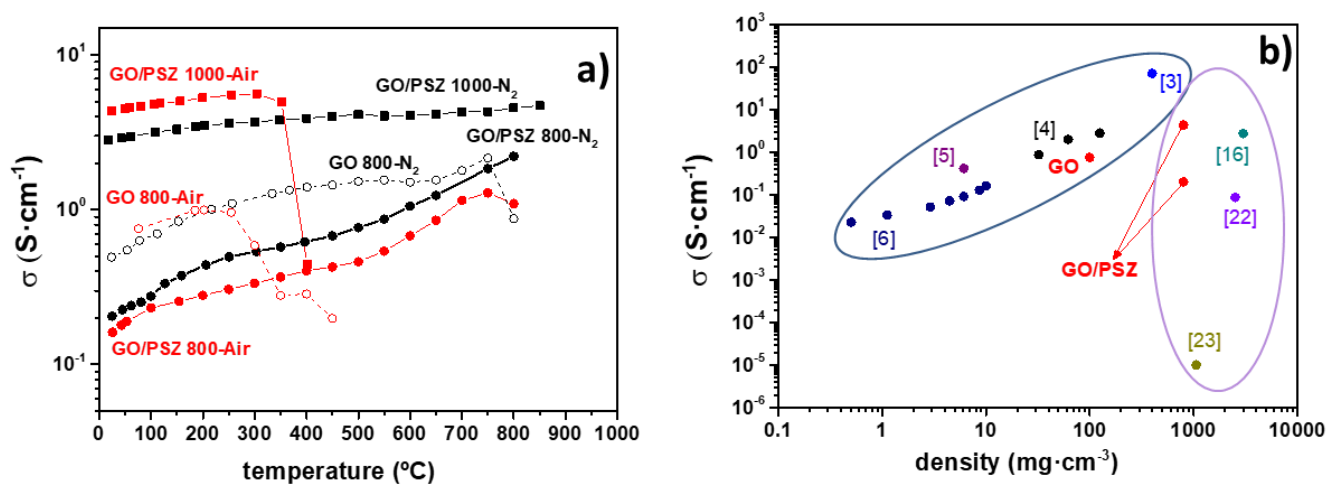

Fig. 4. a) Electrical conductivity vs temperature of the $3 \mathrm{D}$ GO $\left(800^{\circ} \mathrm{C}\right)$ and GO/PSZ $\left(800\right.$ and $1000^{\circ} \mathrm{C}$ ) structures for the testing conditions specified in the legends (air in red and $\mathrm{N}_{2}$ in black), the inset in a) is a scheme of the experimental setting for measuring $\sigma . \mathrm{b}$ ) Comparison of $\sigma$-RT values- of present GO structure with published data from different groups for GO printed structures after reduction treatments (ref [4-6] and also for a 3D GNP structure (ref [3]), all these data appear green encircled. In the same graph, data for diverse graphene-based composite structures (magenta encircled) are drawn, including both polymeric (ref [22,23]) and ceramic matrices ( $\mathrm{SiC}$, ref [16]), along with results for present 3D GO/PSZ materials (marked with arrows).

Another distinctive feature of the 3D GO/PSZ material is its hydrophobic character; in fact, by simply casting a water droplet over the structure an instantaneous absorption was observed in the case of the bare GO scaffolds (treated at $800{ }^{\circ} \mathrm{C}$ ); whereas the ceramic converted specimen composite showed not wetting (contact angle $\theta \geq 120^{\circ}$ ) (Fig. 5a), which is distinctive characteristic of ceramized PSZ coatings. Also exceptional is the thermal protection gained by the infiltrated and pyrolyzed GO structure as reflected in Fig. 5b. Temperatures near $900{ }^{\circ} \mathrm{C}$ are recorded in the inner region of this material (Figs. 5b,c) after three consecutive heating cycles of $30 \mathrm{~s}$ in air using a micro-torch (see inset in Fig. 5b). A remarkably rapid cooling $\left(\sim 700{ }^{\circ} \mathrm{C} \mathrm{min}^{-1}\right)$ was also recorded after removing the torch. Conversely, the GO bare structure showed a more irregular temperature profile during heating with a sudden drop down to $500{ }^{\circ} \mathrm{C}$ (after removing the burner) (see Fig. 5b). This effect is consistent with the occurrence of vaporization and subsequent collapsing of the GO structure on the first heating cycle (see Supplementary data, Fig. S5). 
a)

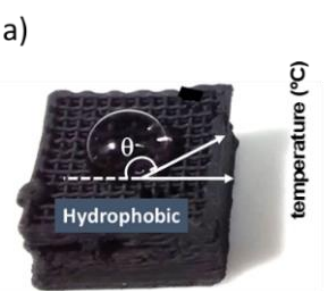

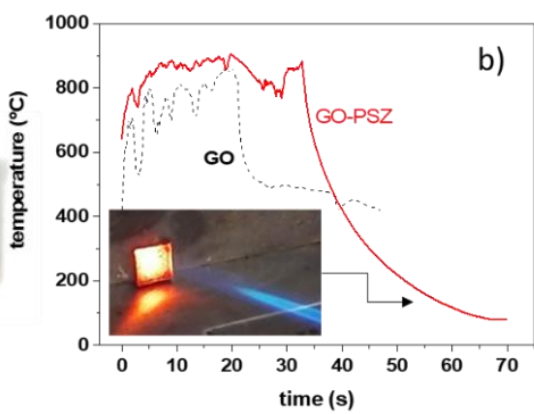

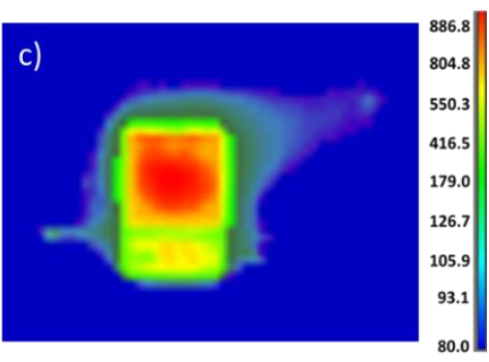

Fig. 5 (a) Image showing the hydrophobic nature of the GO/PSZ structure (treated at $\left.800^{\circ} \mathrm{C}\right)$ denoted by the high wetting angle $\left(>120^{\circ}\right)$ acquired by the water droplet resting on the surface of the structure. b) Average temperature profile of similar GO/PSZ structure with time -while heating with a micro-torch (inset)- reaching temperatures close to $900{ }^{\circ} \mathrm{C}$. Once the micro-torch is removed, the structure coolsdown rapidly $\left(\sim 700^{\circ} \mathrm{C} \mathrm{min}^{-1}\right)$. The plot also shows the temperature profile recorded for the GO structure for comparison. c) Thermographic image of the GO/PSZ structure recorded during the heating test showing a homogenous temperature distribution in the central region, which also reaches the highest temperature.

Finally, a comparison of the mechanical endurance of both types of structures clearly indicates that the $\mathrm{GO} / \mathrm{PSZ}$ composite structures $\left(800{ }^{\circ} \mathrm{C}\right.$ treatment) shows higher crushing stress $(0.3-0.9 \mathrm{MPa})$ than the bare GO structures $(0.1 \mathrm{MPa})$ as seen in Fig. 6 , in accordance with the higher density of the first, although the beneficial mechanical interaction between both phases cannot be discarded, as plenty supported for bulk graphene-based ceramic composites [24]. The composite structures result also stiffer as consequence of the ceramized phase involving the flexible GO skeleton.

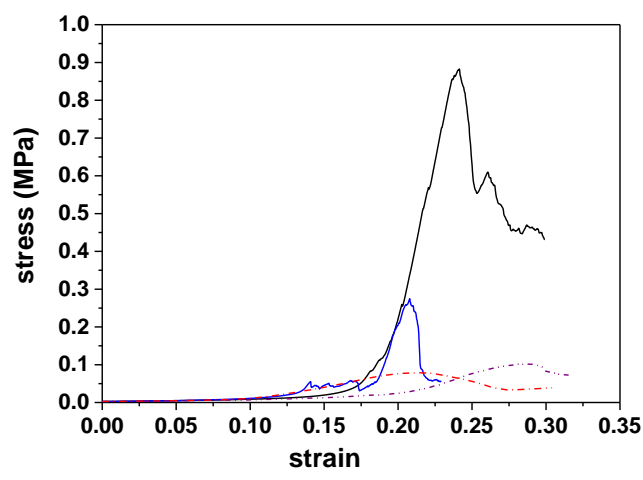

Figure 6. Results for compression tests in the 3D scaffolds in the bare GO structures dried and lyophilized (dotted lines) and for the 3D GO/PSZ structures pyrolyzed at 800 ${ }^{\circ} \mathrm{C}$ (continuous lines). 


\section{Conclusions}

The potential of filament printing for creating 3D GO/ceramic nanocomposites by infiltrating a self-supported 3D GO lattices with a liquid preceramic polymer is demonstrated. Pyrolysis treatments in the range of $800-1000{ }^{\circ} \mathrm{C}$ produce the wrapping of the interlocked GO structure with an amorphous ceramic phase, which guarantees electrical connectivity while provides enhanced protection against atmosphere and temperature (up to $900{ }^{\circ} \mathrm{C}$ in air) to the embedded GO network as well as more robustness. This process could be applied for different preceramic polymers in liquid form and for customized underlying graphene-based 3D structures, thus demonstrating a competitive and versatile way to create strong, conductive and thermal resistant architected graphene-based ceramic composites at very low temperatures.

\section{Acknowledgements}

This work was financed by project MAT2015-67437-R (MINECO/FEDER, UE). JJM acknowledges the financial support of MINECO/FSE (UE) through the FPI contract ref: BES-2016-077759 (2015 call). Thanks are given to Mr. Enrique Biosca for his experimental support.

\section{Appendix A. Supplementary data}

\section{References}

1 Lewis JA. Direct ink writing of 3D functional materials. Adv. Funct. Mater. 2006; 16(17), 2193-2204.

2 Minas C, Carnelli D, Tervoort E, Studart, A. R. 3D printing of emulsions and foams into hierarchical porous ceramics Adv. Mater. 2016; 28, 9993-9999.

3 De la Osa G, Pérez-Coll D, Miranzo P, Osendi MI, Belmonte M. Printing of graphene nanoplatelets into highly electrically conductive three-dimensional porous macrostructures. Chem. Mater. 2016; 28(17), 6321-6328.

4 Zhu C, Han TYJ, Duoss EB, Golobic AM, Kuntz JD, Spadaccini CM et al. Highly compressible 3D periodic graphene aerogel microlattices. Nat. Commun 2015; 6,6962 .

5 García-Tuñon E, Barg S, Franco J, Bell R, Eslava S, D'Elia E, et al. Printing in three dimensions with graphene. Adv. Mater. 2015; 27(10), 1688-1693. 
6 Zhang Q, Zhang F, Medarametla SP, Li H, Zhou C, Lin D. 3D printing of graphene aerogels. Small 2016; 12(13), 1702-1708.

7 Bernardo E, Fiocco L, Parcianello G, Storti E, Colombo P. Advanced Ceramics from Preceramic Polymers Modified at the Nano-Scale: A Review. Materials 2014; 7(3), 1927-1956.

8 Schmidt S, Beyer S, Knabe H, Immich H, Meistring R, Gessler A. Advanced ceramic matrix composite materials for current and future propulsion technology applications. Acta Astronautica, 2004; 55(3), 409-420.

9 Eckel ZC, Zhou C, Martin JH, Jacobsen AJ, Carter WB, Schaedler TA. Additive manufacturing of polymer-derived. Science 2016; 351(6268), 58-62.

10. Zanchetta E, Cattaldo M, Franchin G, Schwentenwein M, Homa J, Brusatin G, Colombo P. Stereolithography of SiOC Ceramic Microcomponents, Adv. Mater. 2016; 28, 370-376.

10 Pierin G, Grotta C, Colombo P, Mattevi C, Direct Ink Writing of micrometric SiOC ceramic structures using a preceramic polymer. J. Eur. Ceram. Soc. 2016; 36(7), 1589-1594.

11 Lukacs A. Polysilazane precursors to advanced ceramics. Am Ceram Soc Bull 2007; 86(1), 9301-9306.

12 Greil P. Polymer derived engineering ceramics. Adv. Eng. Mater. 2000; 2(6), 339-348.

13 Li D, Müller MB, Gilje S, Kaner RB, Wallace GG. Processable aqueous dispersions of graphene nanosheets. Nat. Nanotechnol. 2008; 3, 101-105.

14 T. Tsoufis, F. Katsaros, Z. Sideratou, B. J. Kooi, M. A. Karakassides, A. Siozios. Intercalation study of low-molecular-weight hyperbranched polyethyleneimine into graphite oxide. Chem. Eur. J. 2014; 20(26), 8129-8137.

15 Naficy S, Jalili R, Aboutalebi SH, Gorkin RA, Konstantinov K, Innis PC, Spinks GM, Poulin P, Wallace GG. Graphene oxide dispersions: tuning rheology to enable fabrication. Mater. Horiz. 2014; 1, 326-331.

16 Román-Manso B, Figueiredo FM, Achiaga B, Barea R, Pérez-Coll D, MorelosGómez A, et al. Electrically functional 3D-architectured graphene/SiC composites. Carbon 2016; 100, 318- 328.

17 De Jongh PE, Eggenhuisen TM. Melt infiltration: an emerging technique for the preparation of novel functional nanostructured materials. Adv. Mat. 2013, 25(46), 66726690.

18 Konegger T, Tsai Ch-Ch, Bordia R K. Preparation of polymer-derived ceramic coatings by dip-coating. Mat. Sci. Forum 2015, vols. 825-826, pp 645-652.

19 Mera G, Riedel R, Poli F, Müller K. Carbon-rich SiCN ceramics derived from phenyl-containing poly (silylcarbodiimides). J. Eur. Ceram. Soc. 2009; 29(13), 28732883. 
20 Ni Z, Wang Y, Yu T, Shen Z. Raman spectroscopy and imaging of graphene. Nano. Res. 2008; 184, 273-291.

21 Haluschka C, Engel C, Riedel R. Silicon carbonitride ceramics derived from polysilazanes Part II. Investigation of electrical properties. J. Eur. Ceram. Soc. 2000; 20(9), 1365-1374.

22 Jakus AE, Secor EB, Rutz AL, Jordan SW, Hersam MC, Shah RN. Threedimensional printing of high-content graphene scaffolds for electronic and biomedical applications. ACS nano 2015; 9(4), 4636-4648.

23 Wei X, Li D, Jiang W, Gu Z, Wang X, Zhang Z et al. 3D printable graphene composite. Sci. Rep. 2015; 5, 11181.

24 Miranzo P, Belmonte M, Osendi MI. From bulk to cellular structures: A review on ceramic/graphene filler composites. J. Eur. Ceram. Soc. 2017; 37(13), 3649-3672. 


\section{Supplementary data}

Polymer-derived ceramic/graphene oxide architected composite with high electrical conductivity and enhanced thermal resistance

B. Román-Manso, J. J. Moyano, D. Pérez-Coll, M. Belmonte, P. Miranzo and M. I. Osendi*

Institute of Ceramics and Glass (ICV), CSIC Campus Cantoblanco. Madrid, 28049. Spain.

\section{S1. Wetting ability of the PSZ polymer}

The wetting ability of the polysilazane is tested by casting a drop of PSZ on the surface of a disc specimen produced by pressing the original GO powders; in about $60 \mathrm{~s}$ the drop spreads over the surface as it can be seen in the recorded video shown in Fig. S1.

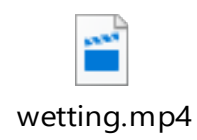

Figure S1. Video showing the wetting and fast spreading of a PSZ droplet over a pressed disc of GO powders.

\section{S2. X-ray diffraction (XRD) analysis of GO/PSZ structures after thermal treatment}

The infiltrated GO structure after pyrolysis treatment is basically amorphous according to the XRD spectra of powered structures (Fig. S2), as just a low intensity wide band around $25^{\circ}$ associated to $\mathrm{C}$ is observed for both pyrolysis temperatures (800 and 1000 $\left.{ }^{\circ} \mathrm{C}\right)$. 


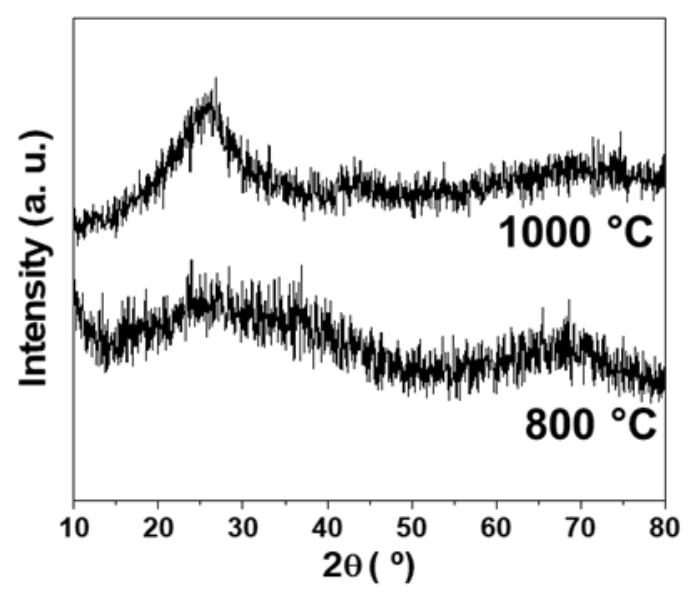

Figure S2. XRD patterns of the GO infiltrated structures pyrolyzed at the shown temperatures.

\section{S3. Transmission electron microscopy (TEM) of the pyrolyzed polymer}

Low magnification TEM image shows glassy aspect (Fig. S3a) of PSZ after thermal treatment $\left(800{ }^{\circ} \mathrm{C}, \mathrm{N}_{2}\right)$. The HRTEM image of Fig. S3b indicates the presence of graphitic domains, as the inter-plane distance of $0.3 \mathrm{~nm}$ evidences, along with small crystalline particles ( $\mathrm{P}$ in the image of Fig. S3b). These incipient crystallizations are identified as SiC according to the FFT (see inset in Fig. S3c)
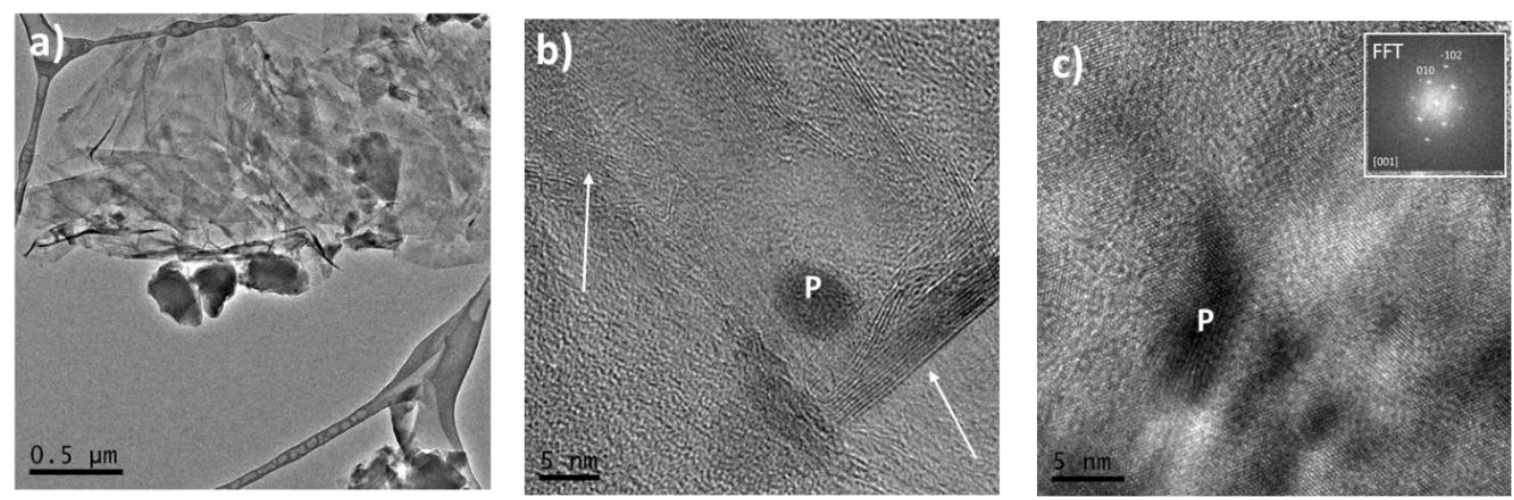

Figure S3. (a) Low magnification TEM image of PSZ treated at $800{ }^{\circ} \mathrm{C}$ under $\mathrm{N}_{2}$ and corresponding HRTEM images in (b) showing graphitic zones (pointed by the arrows) and few small crystalline particles (labelled as P). (c) Small round particle with corresponding FFT indexed as $\alpha-\mathrm{SiC}$. 


\section{S4. SEM Inspection of GO/PSZ structure after electrical conductivity measurements}

Cracking was detected in GO/PSZ structures treated at $1000^{\circ} \mathrm{C}$ after electrical

conductivity measurements as a function of temperature in air, as it is shown in Fig.

S4a. This phenomenon is associated to the differential shrinkage between the amorphous ceramic phase due to progressive densification/crystallization phenomena in the converted polymer and the feeble GO network. Spallation of the outside shell exposing the GO network is perceived in the image, which explains the decrease in electrical conductivity when raising the temperature above $400{ }^{\circ} \mathrm{C}$. The GO/PSZ structures (treated at $800{ }^{\circ} \mathrm{C}$ ) after electrical measurements (up to 800 in air) shows a comparatively less damage (Fig. S4b), which is also reflected by the $\sigma$ results.
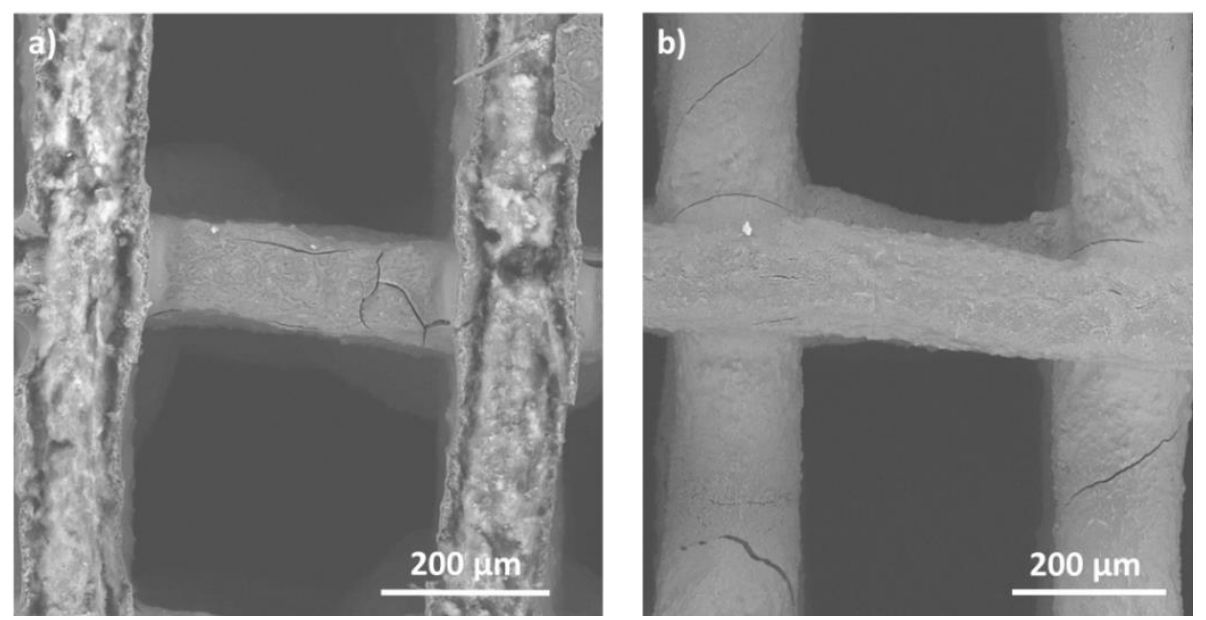

Figure S4. SEM micrographs of 3D GO/PSZ structures after electrical conductivity testing measurements : a) material pyrolyzed at $1000{ }^{\circ} \mathrm{C}$, showing extensive cracking and spall off exposing the GO network after $\sigma$ measurement up to $500{ }^{\circ} \mathrm{C}$, in air. (b) material pyrolyzed at $800{ }^{\circ} \mathrm{C}$ after $\sigma$ measurement up to $800^{\circ} \mathrm{C}$, in air, showing few cracks .

\section{S5. Thermal resistance of the bare GO structures}

The heating of the 3D GO bare structure with the micro-torch and its degradation due to GO vaporization can be seen in Fig. S5a and S6b. The corresponding IR image after 
removing the torch (Fig. S5c) displays an inhomogeneous temperature distribution on the scaffold surface, as yellow and red pixels that correspond to different temperature ranges (see temperature scale in Fig. S5c) are seen. Actually, this temperature difference is fictitious as half of the specimen had evanesced (Fig. S5b); hence, the hotter IR emission (right side on the image of Fig S5c) partially corresponds to the heating of the metal piece supporting the back of the specimen. The green spots captured on the left side of the image (Fig. S5c) reflects the ejection of hot matter from the specimen.
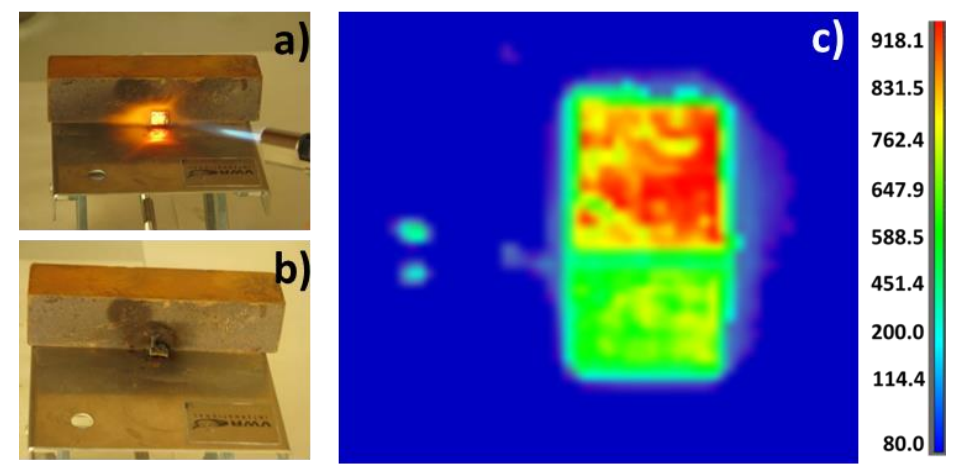

Figure S5. a) Picture of the specimen glowing during the micro-torch heating. b) Image of the degraded specimen -half of the structure vaporized- after removing the heating source. c) Recorded IR image of the heated specimen and attached temperature scale. 